\title{
АНТИТЕЛА IgM И IgG К ВИРУСУ SARS-COV-2 У НОВОРОЖДЕННЫХ ОТ МАТЕРЕЙ С COVID-19
}

\author{
А. А. Семешкин, В. И. Вечорко, Б. В. Силаев $\bowtie$, Н. Н. Левчук, С. В. Поликарпова, О. В. Аверков
}

Городская клиническая больница № 15 имени О. М. Филатова, Москва, Россия

Исследование иммунитета у новорожденных, родившихся от матерей с доказанной новой коронавирусной инфекцией COVD-19, - малоизученный в настоящее время вопрос. Целью работы было проанализировать уровень иммуноглобулинов IgM и IgG k вирусу SARS-CoV-2. Исследование проводили у 20 матерей в возрасте 19-39 лет и 21 новорожденного (родилась одна двойня). В случае обнаружения повышенного уровня иммуноглобулинов ІgМ, IgG к вирусу SARS-CoV-2 у матери у новорожденного выявляли повышенный уровень IgG. Имеется предположение, что иммуноглобулины IgM к вирусу SARS-CoV-2 не проникают через плаценту от матери к ребенку. Во всех наблюдениях исследование с помощью ПЦР у новорожденных показало отрицательный результат, таким образом, вертикального пути передачи COVID-19, по всей видимости, нет. Необходимы дальнейшие исследования.

Ключевые слова: новая коронавирусная инфекция, COVID-19, SARS-CoV-2, пути передачи инфекции, новорожденные, матери, иммунитет новорожденных, иммуноглобулины, IgM, IgG, плацента

Вклад авторов: А. А. Семешкин - сбор материала, забор крови для исследования IgM и IgG у новорожденных, взятие мазков для ПЦР-диагностики у новорожденных, анализ полученных данных, написание статьи; В. И. Вечорко, О. В. Аверков - планирование исследования, анализ полученных данных; Б. В. Силаев - планирование исследования, забор крови для исследования IgM и IgG у матерей, взятие мазков для ПЦР-диагностики у матерей, анализ полученных данных, поиск литературных источников, написание статьи; Н. Н. Левчук - сбор материала, выполнение лабораторных исследований IgM и lgG, анализ полученных данных; С. В. Поликарпова - сбор материала, выполнение ПЦР-диагностики у матерей и новорожденных, поиск литературных источников, анализ полученных данных.

Соблюдение этических стандартов: исследование одобрено этическим комитетом Городской клинической больницы № 15 имени О. М. Филатова (протокол № 5 от 12 мая 2020 г.) все участники исследования и их законные представители подписали добровольное инсормированное согласие на участие в исследовании.

$\triangle$ Для корреспонденции: Борислав Владимирович Силаев ул. Вешняковская, д. 23/1, г. Москва, 111517; drsilaev@yandex.ru

Статья получена: 26.05.2020 Статья принята к печати: 13.06.2020 Опубликована онлайн: 26.06.2020

DOI: $10.24075 /$ vrgmu.2020.036

\section{IgM AND IgG ANTIBODIES AGAINST SARS-COV-2 IN NEONATES BORN TO MOTHERS WITH COVID-19}

Semeshkin AA, Vechorko VI, Silaev BV $\bowtie$, Levchuk NN, Polikarpova SV, Averkov OV

Filatov City Clinical Hospital № 15, Moscow, Russia

Immunity against the novel coronavirus infection in neonates born to mothers with PCR-confirmed COVID-19 is an understudied field of research. The aim of this study was to analyze the levels of IgM and IgG antibodies against SARS-CoV-2. The study was carried out in 20 mothers aged 19 to 39 years and 21 neonates (including a pair of twins). Babies born to mothers with elevated IgM and IgG against SARS-CoV-2 also had elevated IgG. There is a hypothesis that anti-SARSCoV-2 IgM are not passed on to the child across the placenta. In all cases studied in this work, neonates were PCR-negative for the virus, which suggests the absence of vertical COVID-19 transmission. Further research is needed.

Keywords: novel coronavirus, COVID-19, SARS-CoV-2, transmission routes, neonate, mother, neonatal immunity, immunoglobulin, IgM, IgG, placenta

Author contribution: Semeshkin AA — data acquisition, blood collection for antibody tests in neonates, nasopharyngeal swab collection for PCR tests in neonates, analysis of the obtained data, manuscript preparation; Vechorko VI, Averkov OV — study planning, analysis of the obtained data; Silaev BV — study planning, blood collection for antibody tests in mothers, nasopharyngeal swab collection for PCR tests in mothers, data analysis, literature analysis, manuscrip preparation; Levchuk NN — data acquisition, laboratory tests for IgM and IgG, analysis of the obtained data; Polikarpova SV — data acquisition, PCR tests in mothers and neonates, literature analysis, analysis of the obtained data.

Compliance with ethical standards: the study was approved by the Ethics Committee of Filatov City Clinical Hospital No. 15 (Protocol No. 5 dated May12, 2020). Informed consent was obtained from all study participants or their legal representatives.

$\triangle$ Correspondence should be addressed: Borislav V. Silaev

Veshnyakovskaya, 23/1, Moscow, 111517; drsilaev@yandex.ru

Received: 26.05.2020 Accepted: 13.06.2020 Published online: 26.06.2020

DOI: $10.24075 /$ brsmu.2020.036

Исследование иммунитета новорожденных, рожденных от матерей с генетически доказанной новой коронавирусной инфекций COVID-19, представляет большой интерес в связи с продолжающейся пандемией, вызванной COVID-19. B зарубежной литературе имеются лишь единичные работы, посвященные этому вопросу. Представленные авторами данные в отношении иммунитета новорожденных к новой коронавирусной инфекции COVID-19 единичны, а результаты наблюдений требуют дальнейшего углубленного изучения и анализа. Считается, что вертикальный путь передачи новой коронавирусной инфекции COVID-19 от матери к ребенку крайне маловероятен [1]. Описано всего несколько достаточно спорных случаев возможной вертикальной передачи вируса в Китае [2, 3] и в Перу [4].
Согласно действующему руководству ВОЗ, анализы на коронавирус COVID-19 необходимо проводить с помощью полимеразной цепной реакции с обратной транскрипцией (ОТ-ПЦР) как наиболее точного и надежного метода диагностики вирусной инфекции [5]. Он позволяет определить даже очень небольшое количество РНК вируса в биологическом материале человека. Тестирование заболевших на наличие антител IgM и IgG к вирусу SARSCoV-2 в настоящее время применяют достаточно широко, и использование этой методики в отношении новорожденных и матерей представляется достаточно интересным методом для изучения иммунитета новорожденных, родившихся от матерей с генетически доказанной новой коронавирусной инфекцией COVID-19. Целью работы было исследовать 
иммунитет новорожденных, появившихся от матерей с генетически доказанной коронавирусной инфекцией COVID-19. Наличие иммуноглобулинов класса IgG к вирусу SARS-CoV-2 у новорожденных позволяет судить о наличии врожденного иммунитета и носит прогностический характер.

\section{ПАЦИЕНТЫ И МЕТОДЫ}

Для исследования была отобрана группа рожениц $(n=20)$, возраст которых составлял от 19 до 39 лет, поступивших на роды в родильный дом ГКБ № 15 имени О. М. Филатова в период с 01.05.2020 по 20.05.2020. При поступлении в родильный дом всем роженицам была выполнена ПЦРдиагностика COVID-19. Кроме того, на первом-втором дне жизни всем новорожденным ( $n=21$, в одном случае родилась двойня) также проводили ПЦР-исследование. Критерии включения пациенток в исследование: диагностирование COVID-19 в предродовом периоде; наличие легких и среднетяжелых клинических проявлений COVID-19, тяжесть течения заболевания оценивали согласно Временным методическим рекомендациям [6]. Критерии исключения: в исследование не вошли родильницы с ОРВИ, а также родильницы с отрицательными результатами ПЦРдиагностики на PHK вируса SARS-CoV-2.

Лабораторную (молекулярно-биологическую) диагностику новой коронавирусной инфекции (COVID-19) проводили в соответствии с актуальной на момент исследования версией временных методических рекомендаций [6].

Забор биоматериала для ПЦР-диагностики коронавируса SARS-CoV-2 проводили согласно действующим нормативным документам [7]. Этиологическая диагностика новой коронавирусной инфекции COVID-19 заключается в установлении факта инфицирования коронавирусом SARS-CoV-2 на основе выявления в биоматериале от пациента PHK SARS-CoV-2 с использованием методов амплификации нуклеиновых кислот. В нашей лаборатории выделение PHK коронавируса SARS-CoV-2 проводили на тест-системах "Ампли-Тест SARS-CoV-2», разработанных В Центре стратегического планирования и управления медико-биологическими рисками здоровья Федерального медико-биологического агентства (ЦСП ФМБА; Россия).

Проводили тестирование на антитела класса IgM и lgG к штамму вируса SARS-CoV-2 в сыворотке у родильниц и новорожденных на первый-второй день жизни с целью количественного определения антител к вирусу, вызывающему COVID-19. Взятие, транспортировку и хранение биологического материала осуществляли в соответствии с рекомендациями разработчика тест-системы.

Исследования выполняли на анализаторе CL 6000і (Shenzhen Mindray Bio-Medical Electronics Co.; Китай).

Качественное определение антител IgG и IgM к вирусу SARS-CoV-2 (SARS-CoV-2-lgG, SARS-CoV-2-lgM) проводили иммунохемилюминесцентным методом (чувствительность и специсричность метода составляют, согласно данным разработчика, 97,8 и 97,9\% соответственно). Референсные значения для примененной нами методики определения антител класса IgM и $\lg$ к вирусу, вызывающему COVID-19, составляли 0,00-0,999 OCE и 0,00-9,90 Ед./мЛ соответственно.

Родоразрешение проводили через естественные родовые пути $(n=16)$. В четырех наблюдениях было выполнено кесарево сечение в нижнематочном сегменте по общепринятой методике. Все мамы носили маски, все медицинские сотрудники использовали защитные костюмы и маски класса защиты FFP2-3 в соответствии с требованиями эпидемиологического режима.

\section{РЕЗУЛЬТАТЫ ИССЛЕДОВАНИЯ}

Младенцы были изолированы от матерей сразу после родов. Все дети имели на первой минуте рождения 8-9 баллов по Таблица 1. Уровень антител класса IgM и IgG к вирусу COVID-19 у матерей и новорожденных

\begin{tabular}{|c|c|c|c|c|}
\hline \multirow{2}{*}{ Наблюдение } & \multicolumn{2}{|c|}{$\lg M$} & \multicolumn{2}{|c|}{$\lg G$} \\
\hline & У матери & У ребенка & У матери & У ребенка \\
\hline 1 & 2,51 & 0,15 & 0,40 & 0,49 \\
\hline 2 & 8,84 & 0,30 & 34,76 & 11,24 \\
\hline 3 & 9,29 & 0,43 & 136,02 & 109,84 \\
\hline 4 & 0,96 & 0,26 & 0,53 & 0,97 \\
\hline 5 & 1,19 & 0,24 & 17,54 & 15,01 \\
\hline 6 & 0,48 & 0,24 & 0,32 & 0,70 \\
\hline 7 & 2,01 & 0,24 & 24,81 & 9,69 \\
\hline 8 & 1,19 & 0,18 & 92,4 & 42,12 \\
\hline 9 & 6,70 & 0,26 & 116,04 & 24,41 \\
\hline 10 & 6,80 & 0,14 & 66,32 & 89,12 \\
\hline 11 & 0,68 & 0,25 & 1,54 & 1,20 \\
\hline 12 & 0,31 & 0,21 & 0,32 & 0,58 \\
\hline 13 & 14,43 & 0,15 & 38,86 & 23,90 \\
\hline 14 & 2,85 & $\begin{array}{l}1 \text { ребенок 0,14 } \\
2 \text { ребенок 0,16 }\end{array}$ & 47,77 & $\begin{array}{l}1 \text { ребенок } 8,44 \\
2 \text { ребенок } 6,83\end{array}$ \\
\hline 15 & 1,26 & 0,62 & 39,30 & 12,67 \\
\hline 16 & 2,52 & 0,95 & 6,52 & 2,11 \\
\hline 17 & 0,41 & 0,12 & 103,02 & 38,64 \\
\hline 18 & 1,94 & 0,41 & 19,86 & 12,54 \\
\hline 19 & 2,48 & 0,94 & 6,34 & 1,15 \\
\hline 20 & 10,08 & 8,54 & 24,12 & 16,87 \\
\hline
\end{tabular}


шкале Апгар, на пятой минуте - 9-10 баллов. Неонатальные мазки из носа и носоглотки, взятые на первый-второй день жизни, имели отрицательные результаты ПЦР-теста у всех новорожденных. Одновременно с выполнением ПЦРдиагностики COVID-19 выполняли исследование крови на IgM и IgG к вирусу SARS-CoV-2.

В сыворотке у всех новорожденных были обнаружены антитела. У одного младенца были повышены уровни IgM и lgG, у четырех новорожденных уровень IgM и IgG находился в пределах референсных значений, такие же результаты были получены и у матерей. У 14 новорожденных выявлено превышение уровня IgG, при этом у матерей были выше референсных значений и уровень IgM, и уровень IgG (табл. 1).

У всех детей, рожденных от обследованных матерей с подтвержденным COVID-19, PHK вируса SARS-CoV-19 не была обнаружена в мазке из горла методом ПЦР. Тем не менее у всех новорожденных в образцах сыворотки крови были выявлены вирусспецифичные антитела класса IgG.

Уровень IgG был повышен у 16 детей, но в тех же случаях, когда он был повышен и у матери $(n=16)$.

\section{ОБСУЖДЕНИЕ РЕЗУЛЬТАТОВ}

Исходя из полученных нами данных, можно сделать вывод, что, по всей видимости, антитела класса IgG пассивно переносятся кровотоком матери через плаценту к плоду во время конца второго триместра и достигают наибольшего уровня к моменту рождения. По данным других источников, антитела класса IgM, которые в нашем исследовании были обнаружены у одного новорожденного, не передаются от матери к плоду из-за его большого молекулярного веса [1-4]. Однако lgM мог продуцировать сам младенец, если вирус, вызывающий COVID-19, проник в плаценту. Наши данные совпадают с результатами китайских исследователей, полученными на меньшем числе наблюдений [8-10]. Мы не проводили исследование плаценты, поэтому данное суждение всего лишь предположение. Наше наблюдение ограничено небольшим размером выборки, отсутствием исследования вируса и антител в амниотической жидкости и грудном молоке. Тем не менее полученные данные могут быть важны для понимания серологических характеристик новорожденных, чьи матери инфицированы вирусом SARS-CoV-2.

\section{ВЫВОДЫ}

1. В крови новорожденных от матерей с генетически доказанной новой коронавирусной инфекцией COVID-19 на первый-второй день жизни в крови обнаружен повышенный уровень IgG. 2. Повышенный уровень вирусспецифичного IgG может свидетельствовать о наличии врожденного иммунитета к этой инфекции. 3. Отсутствие повышенного уровня вирусспецисичного IgM у новорожденных от матерей с генетически доказанной COVID-19 обусловлено с большой степенью вероятности невозможностью трансплацентарного переноса от матери $\lg$ В в связи с большим молекулярным весом.

\section{Литература}

1. Kimberlin DW, Stagno S. Can SARS-CoV-2 Infection Be Acquired In Utero? More Definitive Evidence Is Needed. JAMA. 2020; 323 (18): 1788-9. DOI: 10.1001/jama.2020.4868.

2. Shaoshuai Wang, Lili Guo, Ling Chen, Weiyong Liu, Yong Cao, Jingyi Zhang, et al. A Case Report of Neonatal 2019 Coronavirus Disease in China. Clinical Infectious Diseases, ciaa225, Available from: https://doi.org/10.1093/cid/ciaa225.

3. Dong L, Tian J, He S, et al. Possible vertical transmission of SARS-CoV-2 from an infected mother to her newborn. JAMA Published March 26, 2020. DOI: 10.1001/jama.2020.4621.

4. Alzamora MC, Paredes T, Caceres D, Webb CM, Valdez LM, La Rosa M. Severe COVID-19 during Pregnancy and Possible Vertical Transmission [published online ahead of print, 2020 Apr 18]. Am J Perinatol. 2020; 10.1055/s-0040-1710050. DOl: 10.1055/s-0040-1710050.

5. World Health Organization. Laboratory testing for 2019 novel coronavirus (2019-nCoV) in suspected human cases: interim guidance 2020. Posted January 17, 2020. Accessed March 5, 2020. Available from: https://www.who.int/publications-detail/ laboratory-testing-for-2019-novel-coronavirus-in-suspectedhuman-cases- 20200117.

6. Временные методические рекомендации МЗ РФ

\section{References}

1. Kimberlin DW, Stagno S. Can SARS-CoV-2 Infection Be Acquired In Utero? More Definitive Evidence Is Needed. JAMA. 2020; 323 (18): 1788-9. DOI: 10.1001/jama.2020.4868.

2. Shaoshuai Wang, Lili Guo, Ling Chen, Weiyong Liu, Yong Cao, Jingyi Zhang, et al. A Case Report of Neonatal 2019 Coronavirus Disease in China. Clinical Infectious Diseases, ciaa225, Available from: https://doi.org/10.1093/cid/ciaa225.

3. Dong L, Tian J, He S, et al. Possible vertical transmission of

«Профилактика, диагностика и лечение новой коронавирусной инфекции (COVID-19)» версия № 6 (24.04.2020). Доступно по ссылке (активна на 09 июня 2020 г.): http://www.garant.ru/ products/ipo/prime/doc/74067237/.

7. Временная инструкция МЗ РФ От 10.04.2020 г. № 17-1/ И1-2004 «Временная инструкция по вопросу забора биологического материала у всех пациентов с подозрением на пневмонию или с подтвержденной пневмонией, поступающих на госпитализацию в стационары». Доступно по ссылке (активна на 11 июня 2020 г.): http://base.garant. $\mathrm{ru} / 74167237 /$.

8. Zeng H, Xu C, Fan J, et al. Antibodies in Infants Born to Mothers With COVID-19 Pneumonia. JAMA. 2020; 323 (18): 1848-9. DOI: 10.1001/jama.2020.4861.

9. Parazzini F, Bortolus R, Mauri PA, Favilli A, Gerli S, Ferrazzi E. Delivery in pregnant women infected with SARS-CoV-2: A fast review. Int J Gynaecol Obstet. 2020 Jul; 150 (1): 41-46. DOI: 10.1002/ijgo.13166. Epub 2020 May 1.

10. Liu P, Zheng J, Yang P, Wang X, Wei C, Zhang S, et al. The Immunologic Status of Newborns Born to SARS-CoV2-infected Mothers in Wuhan, China J Allergy Clin Immunol. 2020 May 10: S0091-6749(20)30640-0. DOI: 10.1016/j.jaci.2020.04.038.
SARS-CoV-2 from an infected mother to her newborn. JAMA. Published March 26, 2020. DOI: 10.1001/jama.2020.4621.

4. Alzamora MC, Paredes T, Caceres D, Webb CM, Valdez LM, La Rosa M. Severe COVID-19 during Pregnancy and Possible Vertical Transmission [published online ahead of print, 2020 Apr 18]. Am J Perinatol. 2020; 10.1055/s-0040-1710050. DOI: 10.1055/s-0040-1710050.

5. World Health Organization. Laboratory testing for 2019 novel 
coronavirus (2019-nCoV) in suspected human cases: interim guidance 2020. Posted January 17, 2020. Accessed March 5, 2020. Available from: https://www.who.int/publications-detail/ laboratory-testing-for-2019-novel-coronavirus-in-suspectedhuman-cases- 20200117.

6. Vremennye metodicheskie rekomendacii MZ RF. «Profilaktika, diagnostika i lechenie novoj koronavirusnoj infekcii (COVID-19), versija \# 6 (24.04.2020). Available from (aktivna na 09 ijunja 2020 g.): http://www.garant.ru/products/ipo/prime/doc/74067237/. Russian.

7. Vremennaja instrukcija MZ RF ot 10.04.2020 g. \# 17-1/11-2004 «Vremennaja instrukcija po voprosu zabora biologicheskogo materiala u vseh pacientov s podozreniem na pnevmoniju ili s podtverzhdennoj pnevmoniej, postupajushhih na gospitalizaciju v stacionary». Available from (aktivna na 11 ijunja 2020 g.): http:// base.garant.ru/74167237/. Russian.

8. Zeng H, Xu C, Fan J, et al. Antibodies in Infants Born to Mothers With COVID-19 Pneumonia. JAMA. 2020; 323 (18): 1848-9. DOI: 10.1001/jama.2020.4861.

9. Parazzini F, Bortolus R, Mauri PA, Favilli A, Gerli S, Ferrazzi E. Delivery in pregnant women infected with SARS-CoV-2: A fast review. Int J Gynaecol Obstet. 2020 Jul; 150 (1): 41-46. DOI: 10.1002/ijgo.13166. Epub 2020 May 1.

10. Liu P, Zheng J, Yang P, Wang X, Wei C, Zhang S, et al. The Immunologic Status of Newborns Born to SARS-CoV2-infected Mothers in Wuhan, China J Allergy Clin Immunol. 2020 May 10: S0091-6749(20)30640-0. DOI: 10.1016/j.jaci.2020.04.038. 